\title{
Rationing of technological properties of asphalt mixtures based on analysis of their structurally- mechanical properties
}

\begin{abstract}
The article is devoted to the forecast and evaluation of the quantitative requirements for mechanical and structural-mechanical properties of asphalt mixtures in the production stage. Constant change of operating conditions of asphalt concrete pavement in Russia, which associated with increasing traffic, increasing axial loads, speed, weather and climate effects and other factors every 10-15 years requires the use of the structural layers of the pavement of the new asphalt mixtures with elevated freight performance characteristics. This is evidenced by the continuous improvement of normative base of technical requirements for asphalt concretein our country and abroad.
\end{abstract}

Volume 3 Issue I - 2017

Kochnev VI, Kotlyarevskiy EV

Professor of Techno sciences, MADI, Russia

Correspondence: Kotlyarevskiy EV, Professor Dr Techno sciences, MADI, Russia, Email eco46@mail.ru

Received: April 21, 2017| Published: July 17, 2017

\section{Introduction}

The analysis of this experience shows that both domestic and foreign regulations do not address the requirements to technological properties of asphalt mixtures. It is known that asphalt mixtures and asphalt concrete on that in Russia and abroad have different classifications and classification attributes are applied to the production machines and mechanisms have significant differences in technological possibilities when laying and compacting of asphalt mixtures in meaningful layers of flexible pavement. When designing Work Project at specific facilities professionals contractors, building on the model advanced technology solutions take into account climatic factors, weather conditions, logistics in the delivery of asphalt concrete mixtures from the asphalt plant to the place of installation, the design of the pavement, real qualifications operators of road-building machines and mechanisms and a ton of other less weighty circumstances, in consequence of the adoption of optimal technological schemes entirely depends directly on vendor-specific works. In other words, the entire final production cycle, from which mainly and formation depends on the structure and properties of asphalt mixtures depends entirely on the qualifications and experience of the contractor.

The experience of the asphalt coating and bases suggests that technology is not always optimal, which ultimately affects the lifetime of the asphalt construction layers and the whole road construction. The formation of an optimum structure and properties of complex composite of polydispersion compound material based on organic binders with complex non-linear rheological properties cannot occur in the case of sub-optimal process parameters during the mixing process in asphalt-mixing plants, the delivery of the mixture, its stowage and its sealing.

It must be borne in mind that technological equipment has different design features and energy capabilities; there may be significant variations in the conditions for road works and design structures of asphalted construction layers and underlying structural layers on roads of different categories. On the basis of theoretical and experimental studies $^{1}$ it is established that asphalt mixtures and asphalt in different technological and operational situations can be regarded as a highly concentrated dispersed system, the properties of which are largely dependent on the physico-chemical processes taking place in the structure of the material. The assessment of these processes needs to take into account the basic laws of physico-chemical mechanics and the specifics of the contact interactions. ${ }^{1,2}$ The main patterns were established by researchers at the School of Academician P. Rebindera on various model trains (2).

To study the structural-mechanical properties of dispersed materials Rebinder \& Mikhailov ${ }^{1,3}$ reviewed the processes of structure formation in view of additivity strength elementary contacts when the limiting shear stress (or strength of disperse system) is from the expression (1).

$$
P_{m}=k_{1} \cdot F_{c} \cdot n^{2 / 3}=k_{2} \cdot F_{c} \cdot \phi \cdot S_{y a ̈}^{2}=k_{3} \cdot F_{c} \cdot \phi \cdot \delta i^{-2}
$$

Where: $P_{m}$-limit shear stress, $\mathrm{P}_{\mathrm{a}}$;

$F_{C}$-average bonding strength in contact between particles, n;

$N$ is the average number of contacts per unit volume $\left(\mathrm{cm}^{3}\right) ; \phi I-$ relative density; $\boldsymbol{S}_{\boldsymbol{y}}$-specific surface mineral part, $\mathrm{cm}^{2} / \mathrm{g}, \boldsymbol{\delta}^{\text {iek }}$-equivalent (weighted average) size of disperse phase particles.

$$
n=6,7373 \cdot e^{5,44 \cdot \phi} \cdot \delta_{i}^{-2}
$$

The average number of individual contacts in unit volume ${ }^{1}$ is determined by the formula (2)

The average force of adhesion in contact by the formula (3), and the average strength of a single contact from equation (4)

$$
\begin{gathered}
F_{c}=P_{m} \cdot \delta^{2} \cdot \frac{\rho^{\prime}}{\rho_{\pi}} \cdot \frac{\left(1-\phi_{\grave{\partial}}\right) \cdot(1-\phi)}{\left(\phi_{\grave{\partial}}-\phi\right)} \\
P_{i}=\frac{F_{c}}{S_{i}}=\frac{P_{m}}{n^{1 / 3}}
\end{gathered}
$$


Where: $P_{m}, F_{c}, n, \delta^{j e k v}$-same as (1) $r$-relative density of the dispersed phase (resulting from technological impacts and absolutely devastated-loose State, $\boldsymbol{r}$ 'is the density of the particles of the dispersed phase and $\boldsymbol{r} \boldsymbol{n}$-density of asphalt concrete.

Without an analysis of the processes of asphalt mixtures material generation, the effects of technological factors cannot be explained by the processes of structure and destruction of the structure in the design of road garments. In the works ${ }^{3,4}$ authors developed the technique of designing asphalt mixes with the requisite structural-mechanical properties, which is implemented on computer. ${ }^{5}$ The formation and destruction of the structure of the asphaltic mixture and asphalt at various technological stages is shown in Figure 1.

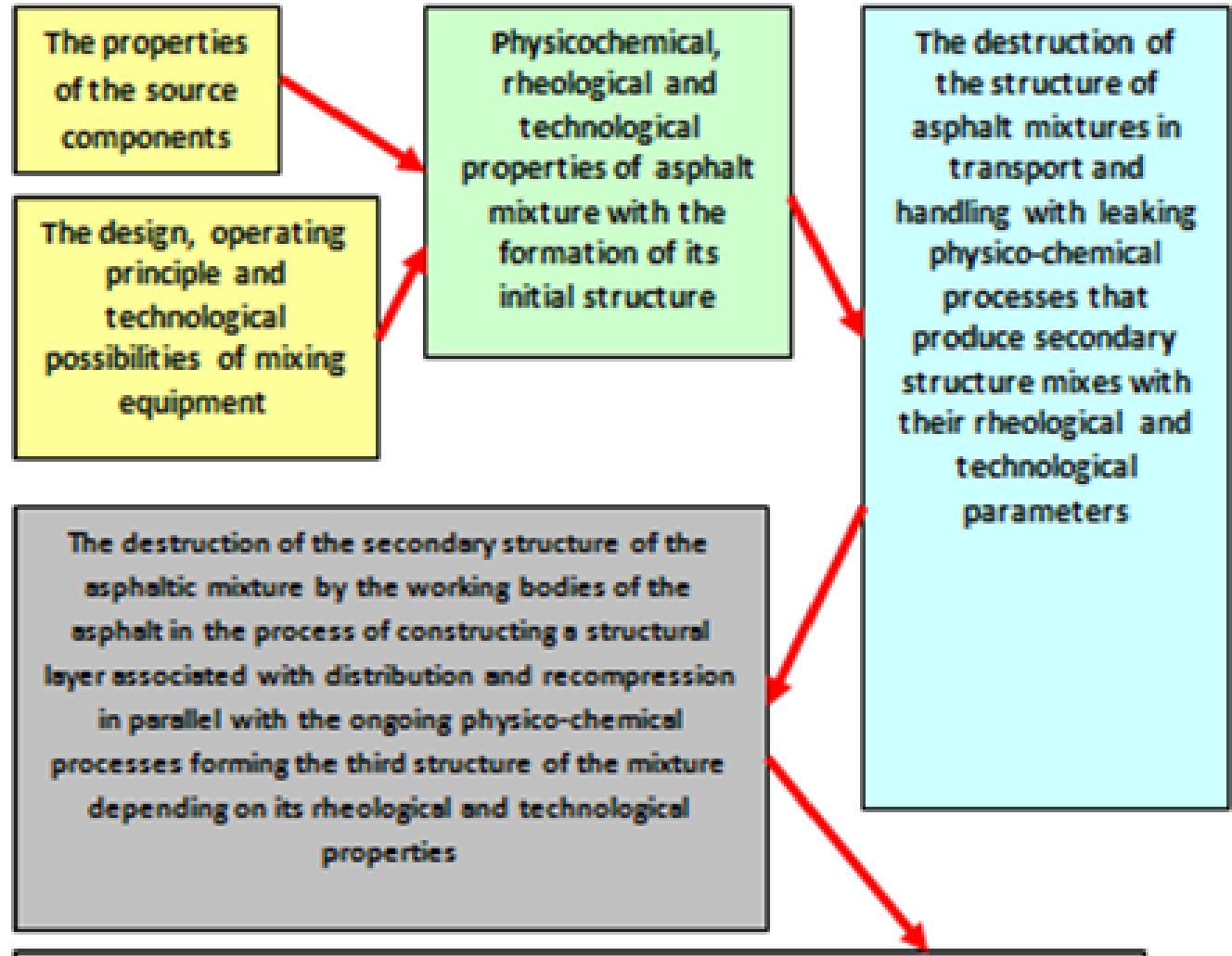

The repeated destruction and formation of the structure of the hot asphaltic mixture with the compaction effect of the road roller link in the constantly changing structural and mechanical characteristics of the sealed mixture and the compressed asphalt. Working bodies asphalt in the process of the device. It also continues to governing physico-chemical processes at the border of bitumen-stone material with the formation of

the micro, meso and macro-contact structure of the asphalt mixtures mixture until the final structure of the compressed hot asphalt is achieved.

The final formation of the structure of the cooling asphalt layer, with continuing cross linking silicones physico-chemical processes at the borders of the section with the formation of the micro, the meso-and makrokontaktnoj structure of the Bitumomineral'nogo material with the optimum (or close to optimal) structure of the asphalt, providing the required set of construction and technical properties guaranteeing the reliable operation of the asphalted construction layer during the required life.

Figure I Formation and destruction of structure of asphalt mixtures and the blacktop to various technological stages. 
For the analyze of changes for the limit values of the structurallymechanical properties of asphaltic concrete technical requirements for normalized GOST 9128 indicators of physical and mechanical properties for the various types and types of asphalt I, II and III of the mark for all the Russian climate zones were used. They are the tensile strength at $50^{\circ} \mathrm{C}$ fixed temperatures and speeds of 3 and $50 \mathrm{~mm} / \mathrm{min}$ $\left(R_{50}^{3}, R_{50}^{50}\right)$, the tangent of the internal friction angle $(\operatorname{tg} \varphi)$ and the clutch $(c)$. Using the Coulomb's formula (5), the shear stress values were found, by expressions (2) and (4) the average clutch limit values in the contact between the particles and the average strength of the single contact

$$
P_{m}=R_{50} \cdot \operatorname{tg} \phi+c
$$

Where:- $R_{50}$-the limit of tensile strength at $50^{\circ} \mathrm{C}$ temperature and $50 \mathrm{~mm} / \mathrm{min}$ deformation speed $\operatorname{tg} \varphi$-tangent of the internal friction angle, $c$-chaining.

The change in shear stress, depending on the tensile strength of $50^{\circ} \mathrm{C}$ and the $50 \mathrm{~mm} / \mathrm{min}$ test speed for all asphalt tags in all road and climate zones, has been processed on the computer. A correlative regression analysis was used for linear, progressive, logarithmic, and exponential mathematical constraints. Preference was given to the most simple regression of a linear view with the required accuracy and adequacy (6).

$$
P_{m}^{50}=b_{1} \cdot R_{50}+b_{0}
$$

Where $b_{0}$ and $b_{1}$-regression coefficients.

Obtained by calculations and ratios of multiple regression coefficients of correlation for asphalt I, II and III of the stamps are shown in the Table 1. Analytical expressions derived dependencies for different brands in different road-climatic zones have equal regression coefficients and high rates of multiple correlations. In Figure 1 shows a generalized correlation changes limiting shear stress by compressive strength at temperature $50^{\circ} \mathrm{C}$. Realization of the obtained relationships has made it possible to define requirements to limit the voltage shift of standard GOST 9128 temperature tests, which are shown in the Table 2. Figure 2 shows a prediction of the change in the tensile strength of the compression and shear stress in the wide range of operating and technological temperatures.

Table I Regression coefficients and coefficients of multiple correlations for asphalt I, II and III mark showing

\begin{tabular}{llll}
\hline \multirow{2}{*}{ Mark of asphalt } & \multicolumn{2}{l}{$\begin{array}{l}\text { Regression } \\
\text { coefficients }\end{array}$} & $\begin{array}{l}\text { The coefficient } \\
\text { of multiple } \\
\text { correlation }\end{array}$ \\
\cline { 2 - 4 } & $\mathbf{b}_{0}$ & $\mathbf{b}_{1}$ & 0,9772 \\
\hline I II & 0,1365 & 0,9940 & 0,9818 \\
III & 0,1357 & 0,9857 & 0,9466 \\
\hline
\end{tabular}

Table 2 Limited shear stress requirements $\left(P_{m}\right)$

\begin{tabular}{llcc}
\hline & \multicolumn{3}{l}{ Limited shear stress, MPa } \\
\cline { 2 - 4 } Test temperature, ${ }^{\circ} \mathrm{C}$ & \multicolumn{3}{l}{ Asphalt mark } \\
\cline { 2 - 4 } & $\mathbf{I}$ & $\mathbf{2}$ & 3 \\
\hline 0 & $<8$ & $<9$ & $<10$ \\
20 & $>3,0$ & $>3,5$ & $>4,0$ \\
50 & $>1,0$ & $>1,0$ & $>1,0$ \\
\hline
\end{tabular}

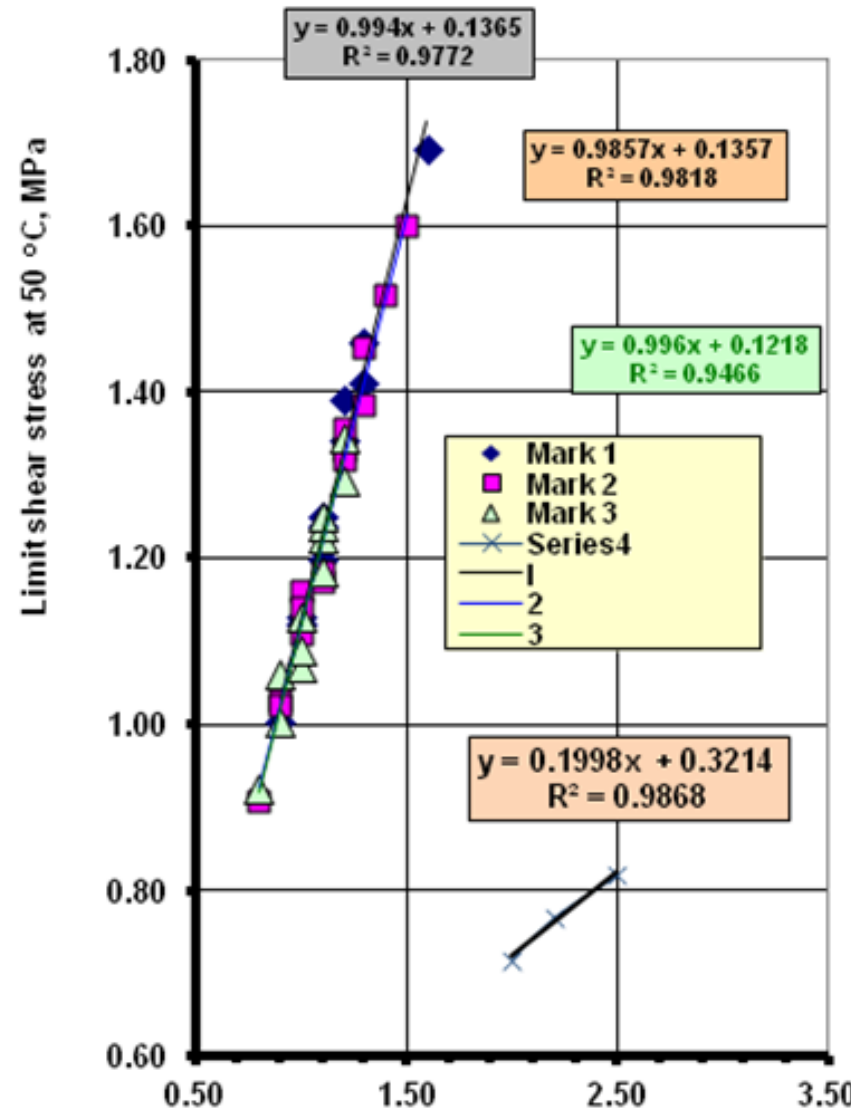

Limit compressive strength in $50^{\circ} \mathrm{C}, \mathrm{MPa}$

Figure 2 Change of shear stress limit depending on the compressive strength at $50^{\circ} \mathrm{C}$.

The operating temperature can be assigned within the interval from- 20 to $50^{\circ} \mathrm{C}$. To technology from +80 to $+160^{\circ} \mathrm{C}$. In Figure 3 presents the exponential regression model compressive strength changes depending on the temperature of the test. Dependency analysis enables you to draw conclusions that the regression coefficients with increasing brand asphalt concrete (from III to I) decreasing, indicating a lower temperature sensitivity of asphalt concrete of Mark I. Figure 3 shows a prediction of the change in the tensile strength of the compression and shear stress in the wide range of operating and technological temperatures. 


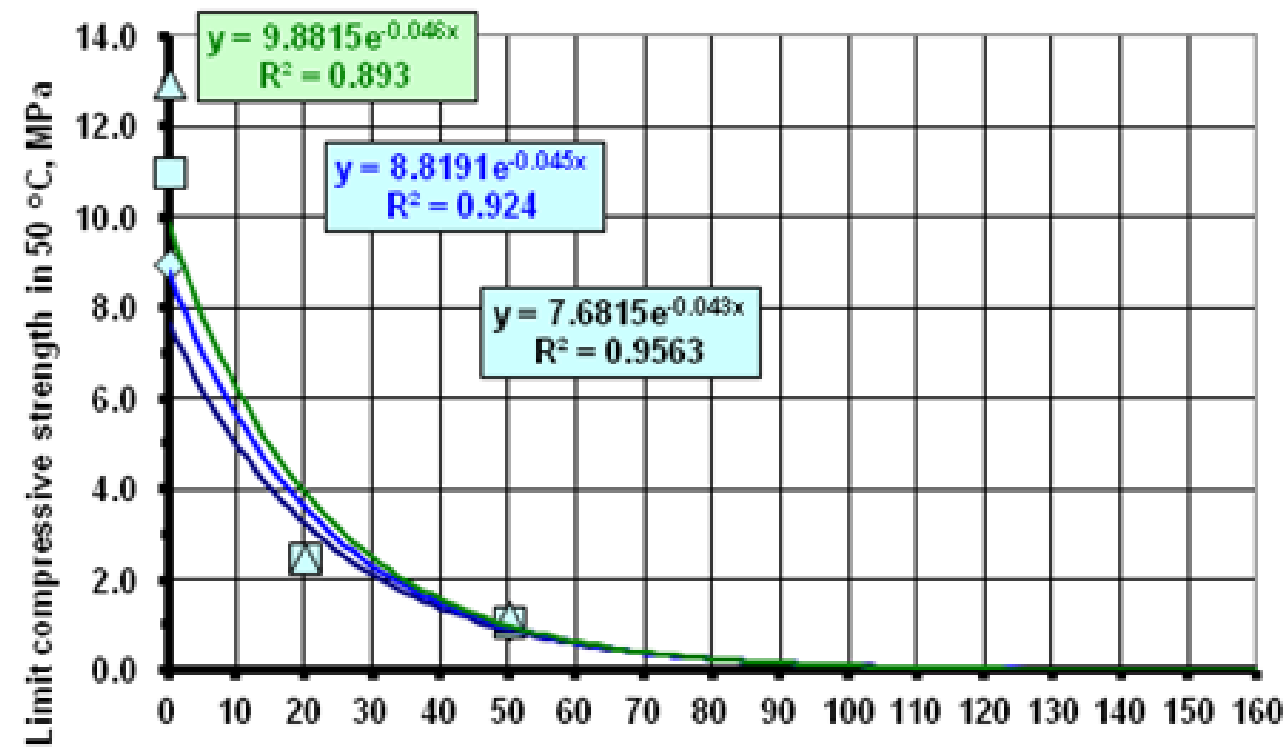

Temperature, ${ }^{\circ} \mathrm{C}$

Figure 3 Forecast changes in compressive strength and shear stress limit in a wide range of operational and technological temperature.

Table 3 Forecast indicators of mechanical properties

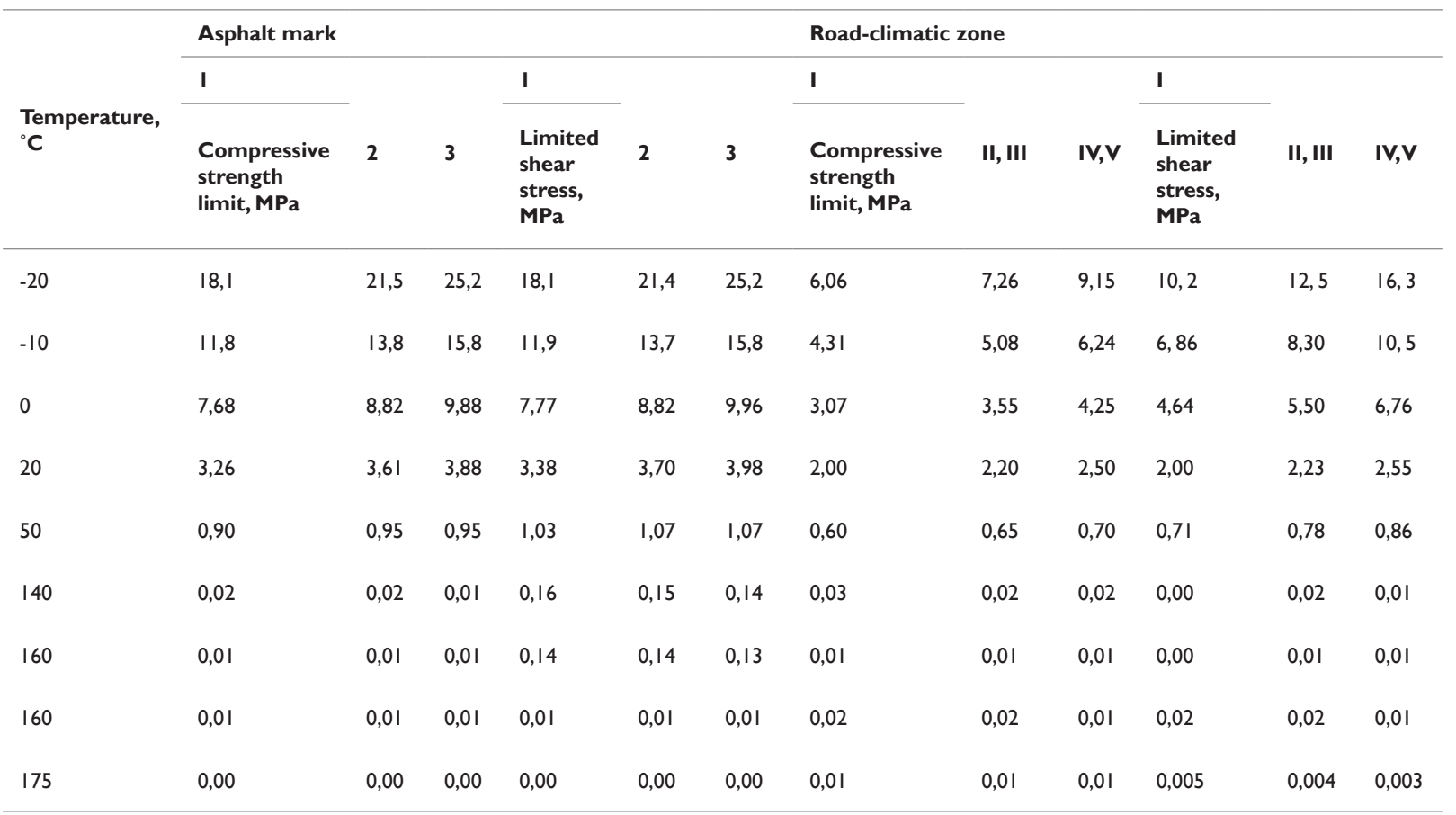

Table 4 Requirements for the technological properties of asphalt mixtures at compaction

\begin{tabular}{|c|c|c|c|}
\hline \multirow{4}{*}{ Compaction } & & The end of the compaction & 250 \\
\hline & strength, Kra & The beginning of the compaction & 90 \\
\hline & & The end of the compaction & 390 \\
\hline & & The beginning of the compaction & 220 \\
\hline
\end{tabular}


The operating temperature can be assigned within the interval from -20 to $50^{\circ} \mathrm{C}$. To technology from +80 to $+160^{\circ} \mathrm{C}$. In Figure 3 presents the exponential regression model compressive strength changes depending on the temperature of the test. Dependency analysis enables you to draw conclusions that the regression coefficients with increasing brand asphalt concrete (from III to I) decreasing, indicating a lower temperature sensitivity of asphalt concrete of Mark I. The obtained values make it possible to develop technological schemes for the preparation of asphalt mixtures at asphalt plants, taking into account the capabilities and technical parameters of asphalt installations, taking into account their design and energy capabilities. You can manage process processes by changing the preparation temperature of the mixture and varying the duration of the mixing in the mixing of the periodic activity or the rate of supply of the original materials (continuous).

In the development of the compression technology, the work projects need to implement a more multi-factor, unstationary task, taking into account weather and climate conditions, the range of transporting the mixture, composition, mass parameters and type of sealing machines at the link of road roller skating, the sequence of their movement on the Mikrozahvatke, the number of passes on one track and much other. In our opinion, the results can be useful to developers of asphalt mixing and compaction equipment for road and construction.

\section{Acknowledgments}

None.

\section{Funding}

None.

\section{Conflicts of interest}

The authors declare there is no conflict of interests.

\section{References}

1. Kotlyavskiy EV. Structuring of highly dispersed materials with light contact seal process interactions (for example, asphalt concrete). Chernomaz Kolloidnyi Zhurnal Item. 1987;1:72-76.

2. Mikhailov NV, Mikhailov NV, Rebinder PA. 1955;17(2):107.

3. Kotlyarskiy EV. Design technique of composition of asphalt concrete mixtures with the requisite structural-mechanical properties. Report to the plenary of the Interstate Association of researchers asphalt Moscow; 2000 .

4. Kotlyarskiy EV. Calculation-experimental design technique bituminous concrete composition, taking into account the structural-mechanical characteristics of asphalt mixtures. Reports of the annual scientific session of the association of researchers of asphalt concrete Moscow, MADI (STU);2007:62-66.

5. Kochnev VI. Selection of mixes. Automating the design composition and quality management in the production of asphalt mixtures with the requisite structural-mechanical properties. 2013;1(974):68-70. 